\title{
Simplified Thermal Model and Optimal Control for Chilled Water Pipe in Air-Conditioning System
}

\author{
Zhida Zhao $\mathbb{D}^{1},{ }^{1}$ Nanyang $Y u\left(\mathbb{D},{ }^{1}\right.$ Tao $Y u,{ }^{1}$ and Lisha $\mathrm{Ye}^{2}$ \\ ${ }^{1}$ School of Mechanical Engineering, Southwest Jiaotong University, Chengdu, China \\ ${ }^{2}$ College of Civil Aviation, Nanjing University of Aeronautics and Astronautics, Nanjing, China \\ Correspondence should be addressed to Nanyang Yu; rhinos@126.com
}

Received 20 September 2018; Revised 27 January 2019; Accepted 14 February 2019; Published 27 February 2019

Academic Editor: Libor Pekař

Copyright (c) 2019 Zhida Zhao et al. This is an open access article distributed under the Creative Commons Attribution License, which permits unrestricted use, distribution, and reproduction in any medium, provided the original work is properly cited.

\begin{abstract}
As an important subsystem in air-conditioning system, water system connects the chiller and terminal equipment. Therefore, it is necessary to develop an accurate thermal model for chilled water pipe to create the suitable indoor temperature and humidity environment. In this paper, the thermal model of the pipe was considered by utilizing the simplified thermal time-delay statespace model with the mass, energy balance, and heat consumption equations. Based on this improved model, the preview control as control strategy for water pipe temperature was proposed, and its robustness and stability were discussed. Subsequently, the performances of this model and control strategy were tested in a fan-coil system simulating with MATLAB and TRNSYS (Transient System Simulation Program). Explicitly, the results show that this model accurately predicts the thermal characteristic, and the average mean squared errors for water temperature were $11.14 \%$ and $12.82 \%$, respectively. Meanwhile, the tracking effect of valve controller was better than the control strategy with no preview control.
\end{abstract}

\section{Introduction}

Currently, the main energy consumption in buildings is caused by air-conditioning system. As the basic subsystem, air conditioning water system (ACWS) creates a comfortable and healthy indoor environment for people through delivering the cold and heat energy, and the pipe network is the most important component. In particular, ACWS which increases the energy consumption and investment has become more complex. Therefore, the development of pipe thermal model is propitious to effectively optimize the control schemes and reduce the energy consumption.

In the past, many researches focused on the heat transfer and transition in ACWS [1]. For instance, Schnedel et al. [2] formulated the flow path model of various components and pipes in the cooling water system similar to the actual electronic system. Ankur et al. [3] analyzed the hydraulic characteristics of the water pipe using the 3D numerical simulation and optimized the heat transfer power of the heat exchanger. Based on the simulation result, an improvement measure for the condenser was proposed. Bram et al. [4] developed a steady-state thermal behavior model of double thermal network pipes and analyzed the influence of temperature and pipe size on the heat loss. However, the thermodynamic state in the actual pipe is dynamic, so some scholars put the direction of pipe thermal model to the dynamic model. In the dynamic model, state-space model and its special types have been considered as the typical ones. State-space model can clearly represent the dynamic relationship between the input and output at system level, and it is easy to study the dynamic coupling and the essence of component models. Then, the accurate prediction model and pipeline structures optimization could be achieved by combining with various algorithms. For instance, Thosar et al. [5] established a nonlinear water system pipe dynamic model with state-space model and energy balance principle. Yao et al. $[6,7]$ proposed a transient response model for constituent elements in the refrigeration cycle system with state-space model. Results showed that these models, with high prediction accuracy, were simple and easy to understand. As an important classification in statespace models, time-delay state-space model is more close to the real system and reflects the time delay. Therefore, 
this model provides a new direction for air conditioning system modeling. To sum up, time-delay state-space model is just widely used in mathematics, electronic information, and control engineering [8-11]. Unfortunately, the applications of time-delay state-space in the air conditioning system are relatively less than other basic models. Based on the air conditioning model, the performance of controller can be improved using some intelligence algorithm, for instance, artificial neural network, fuzzy theory, model predictive control, particle swarm optimization, and genetic algorithm. In these control algorithms, preview control, which can be closely correlated to state space model, is one of the approaches available for producing a good performance by utilizing future information of the reference signal in the controller. Currently, preview control had been researched in servo-system control, robot control [12], spacecraft control [13], and generator set control [14]. Meanwhile, some future state signals and interference signals in the air conditioning system can be predicted, even without model. So, preview control can be used in the air conditioning control.

The main purpose of this study is to present a simple thermal time-delay state-space model (T-SII model) for chilled water pipe in air-conditioning system, and a temperature control strategy for water pipe was proposed using preview control. Subsequently, the performances of T-SII model and preview controller were verified by an existing experimental platform. Results show that this model ensured high reliability and accuracy, and it will provide a guidance and reference for modeling in other air conditioning subsystems. Meanwhile, the delay time was compensated using preview control with the robustness and stability, and the tracking effect of valve controller was improved.

\section{Model}

2.1. Modeling Process. The modeling flow diagram is shown in Figure 1.

Step 1. For modeling of the water loop, the following simplified conditions are necessary:

(a) The water temperature difference between the supply and the return is $5^{\circ} \mathrm{C} \sim 7^{\circ} \mathrm{C}$, so the density of water can be regarded as a constant.

(b) The temperature and flow are only considered in the description of water state in the pipe.

(c) The average water temperature of the inlet and outlet pipe is regarded as a mixed value.

(d) The thermal resistance of the water pipe shell is converted into the insulating layer.

Then, the subspaces with different performance can be obtained [15]. The complex air conditioning water system pipe network is established by connecting these components in turn, and the energy conservation in pipes includes heat

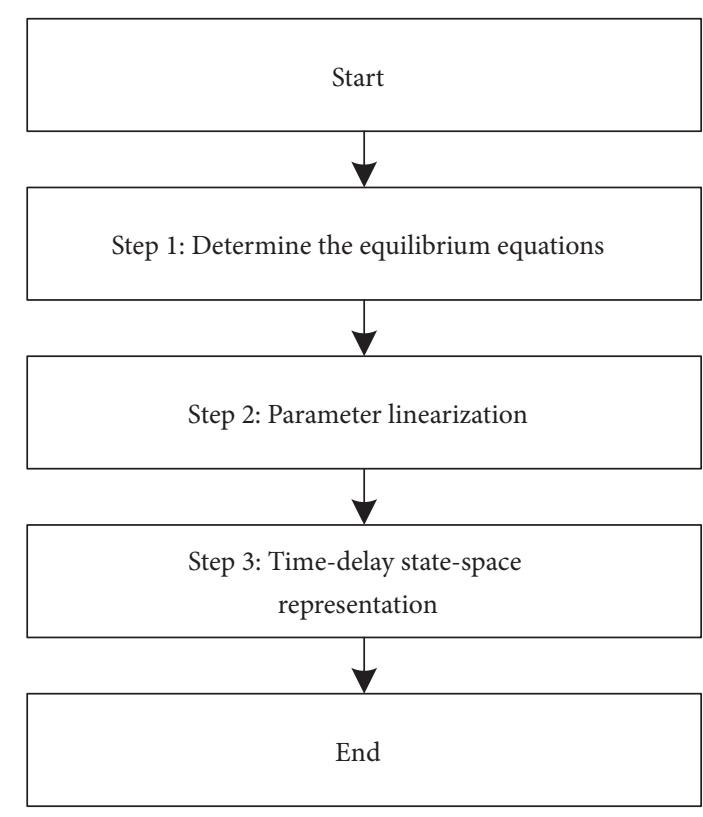

Figure 1: Modeling flow diagram.

transfer and convection. For the normal pipe, its thermal dynamic characteristics can be expressed as [16]

$$
\frac{\partial T}{\partial t}=\underbrace{-\mu \frac{\partial T}{\partial x}}_{\text {thermal transfer }}+\underbrace{\frac{h L}{F c_{p} \rho}\left(T_{\text {env }}-T\right)}_{\text {thermal convection }}
$$

Step 2. The basic variables (temperature and flow rate) can be considered as the fundamental and the lumped variables. The fundamental variables include the temperature and water flow rate. These variables can be considered as the sum of initial value and small increment. The lumped variables include mass specific heat $(c)$ and coefficient of convection heat transfer $(h)$, and these variables can be linearized using first-order Taylor formula.

Step 3. Through parameter linearization, the input variables, output variables, and state variables can be determined according to the import and export status. Generally, the entry parameter and exit parameter are considered as the input variable and output variable, respectively, and the selection about state variable can be the entrance or exit parameter. Then, all equilibrium equations are summarized into unified matrix representations. Finally, the T-SII model will be obtained with respect to the above process.

2.2. Pipe Thermal Model. Pipe occupies the large proportion in the ACWS, and the thermal time delay in the pipe is the most obvious phenomenon. Water pipe network system can be divided into a certain number of straight pipes, which has analogous inlet and outlet parameters. The parameters of the pipe are shown in Figure 2.

The mass conservation equation for the water flowing through pipe can be expressed as

$$
G_{\mathrm{p}(k), \text { in }}=G_{\mathrm{p}(k), \text { out }}=G_{\mathrm{p}(k), \mathrm{z}}
$$




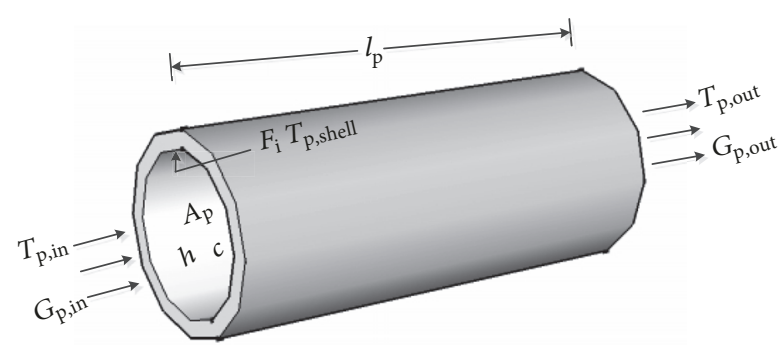

FIGURE 2: Schematic for the working process of pipe.

According to (1) and the assumed condition (c), mass and energy equation for water thermal state along the flow direction can be expressed using linear increment [17]:

$$
\begin{aligned}
& \frac{1}{2} c_{\mathrm{p}(k), \mathrm{w}} M_{\mathrm{p}(k), \mathrm{w}} \frac{d}{d t}\left(T_{\mathrm{p}(k), \text { in }}+T_{\mathrm{p}(k), \text { out }}\right) \\
& =G_{\mathrm{p}(k) \text {,in }} \mathcal{c}_{\mathrm{p}(k), \mathrm{w}}\left(T_{\mathrm{p}(k) \text {,in }}-T_{\mathrm{p}(k), \text { out }}\right) \\
& \quad+h_{\mathrm{p}(k), \mathrm{w}} F_{\mathrm{p}}\left(T_{\mathrm{p}(k), \text { shell }}-\frac{T_{\mathrm{p}(k) \text {,in }}+T_{\mathrm{p}(k), \text { out }}}{2}\right)
\end{aligned}
$$

The mass and energy equation for water thermal state along the shell direction can be expressed as

$$
\begin{aligned}
c_{\mathrm{p}(k), \mathrm{ps}} & M_{\mathrm{p}(k), \mathrm{ps}} \frac{d}{d t}\left(T_{\mathrm{p}(k), \mathrm{ps}}\right) \\
= & \frac{l_{\mathrm{p}}}{R_{\mathrm{p}(k), \mathrm{ps}}}\left(T_{\mathrm{env}}-T_{\mathrm{p}(k), \mathrm{ps}}\right) \\
& \quad+h_{\mathrm{p}(k), \mathrm{w}} F_{\mathrm{p}}\left(\frac{T_{\mathrm{p}(k), \text { in }}+T_{\mathrm{p}(k), \mathrm{out}}}{2}-T_{\mathrm{p}(k), \mathrm{ps}}\right)
\end{aligned}
$$

Two kinds of variables are considered in the equations: the fundamental and the lumped variables. The water temperature and water flow rate are included in fundamental variables, which can be considered as the summation of initial value and a small increment

$$
\begin{aligned}
& T=(T)_{s}+\Delta T, \\
& G=(G)_{s}+\Delta G
\end{aligned}
$$

The lumped variables mainly include the coefficient $(h)$ of heat, which can be linearized using the first-order Taylor formula:

$$
h_{\mathrm{p}(k), \mathrm{w}}=\left(h_{\mathrm{p}(k), \mathrm{w}}\right)_{\mathrm{s}}+\frac{\partial h_{\mathrm{p}(k), \mathrm{w}}}{\partial G_{\mathrm{p}(k), \text { in }}} \cdot \Delta G_{\mathrm{p}(k), \text { in }}
$$

Through the linearized parameters, (3) and (4) can be transformed as follows:
The mass and energy equation for water thermal state along the flow direction

$$
\begin{aligned}
K_{1} & \left(\frac{d}{d t} \Delta T_{\mathrm{p}(k), \text { out }}+\frac{d}{d t} \Delta T_{\mathrm{p}(k), \text { in }}\right) \\
= & X_{\mathrm{p}(k), 1} \Delta T_{\mathrm{p}(k), \text { out }}+X_{\mathrm{p}(k), 2} \Delta T_{\mathrm{p}(k) \text {,shell }} \\
& +X_{\mathrm{p}(k), 3} \Delta T_{\mathrm{p}(k) \text { in }}+X_{\mathrm{p}(k), 4} \Delta G_{\mathrm{p}(k), \text { in }}
\end{aligned}
$$

where

$$
\begin{aligned}
& K_{1}=\frac{1}{2} c_{\mathrm{p}(k), \mathrm{w}} M_{\mathrm{p}(k), \mathrm{w}} \\
& X_{\mathrm{p}(k), 1}=-\left(G_{\mathrm{p}(k), \text { in }}\right)_{s}-\frac{F_{\mathrm{p}}}{2}\left(h_{\mathrm{p}(k), \mathrm{w}}\right)_{s} \\
& X_{\mathrm{p}(k), 2}=F_{\mathrm{p}}\left(h_{\mathrm{p}(k), \mathrm{w}}\right)_{s} \\
& X_{\mathrm{p}(k), 3}=\left(G_{\mathrm{p}(k), \text { in }}\right)_{s}-\frac{F_{\mathrm{p}}}{2}\left(h_{\mathrm{p}(k), \mathrm{w}}\right)_{s} \\
& X_{\mathrm{p}(k), 4}=\left(T_{\mathrm{p}(k) \text {,in }}-T_{\mathrm{p}(k), \text { out }}\right)_{s} \\
& \quad+F_{\mathrm{p}}\left(\left(T_{\mathrm{p}(k), \text { shell }}-\frac{T_{\mathrm{p}(k), \text { in }}+T_{\mathrm{p}(k), \text { out }}}{2}\right)\right. \\
& \quad \cdot\left(\frac{\partial h_{\mathrm{p}(k), \mathrm{w}}}{\partial G_{\mathrm{p}(k), \text { in }}}\right)_{s} \\
& C_{\mathrm{s}}=F_{\mathrm{p}}\left(T_{\mathrm{p}(k), \text { in }}-T_{\mathrm{p}(k), \text { out }}\right)_{s}+h_{\mathrm{s}}\left(T_{\mathrm{p}(k) \text { shell }}\right. \\
& \left.\quad-\frac{T_{\mathrm{p}(k) \text { in }}+T_{\mathrm{p}(k) \text { out }}}{2}\right)_{s}
\end{aligned}
$$

The mass and energy equation for water thermal state along the shell direction

$$
\begin{aligned}
K_{2}\left(\frac{d}{d t} \Delta T_{\mathrm{p}(k) \text {,shell }}\right)= & Y_{\mathrm{p}(k), 1} \Delta T_{\mathrm{p}(k), \text { out }} \\
& +X_{\mathrm{p}(k), 2} \Delta T_{\mathrm{p}(k) \text {,shell }} \\
& +X_{\mathrm{p}(k), 3} \Delta T_{\mathrm{p}(k) \text {,in }} \\
& +X_{\mathrm{p}(k), 4} \Delta G_{\mathrm{p}(k), \text { in }}
\end{aligned}
$$

where

$$
\begin{aligned}
& K_{2}=c_{\mathrm{p}(k), \text { shell }} M_{\mathrm{p}(k) \text { shell }} \\
& Y_{\mathrm{p}, 1}=Y_{\mathrm{p}(k), 3}=\frac{F_{\mathrm{p}}}{2}\left(h_{\mathrm{p}(k), \mathrm{w}}\right)_{s} \\
& Y_{\mathrm{p}(k), 2}=-F_{\mathrm{p}}\left(h_{\mathrm{p}(k), \mathrm{w}}\right)_{s}-\frac{l_{\mathrm{p}(k)}}{R_{\mathrm{pg}}} \\
& Y_{\mathrm{p}(k), 4} \\
& \quad=F_{\mathrm{p}}\left(\frac{T_{\mathrm{p}(k), \text { in }}+T_{\mathrm{p}(k) \text { out }}}{2}-T_{\mathrm{p}(k), \text { shell }}\right)_{s}\left(\frac{\partial h_{\mathrm{p}(k), \mathrm{w}}}{\partial G_{\mathrm{p}(k), \text { in }}}\right)_{s}
\end{aligned}
$$


Combining (7) and (9), the basic thermal time-delay state-space model for the water pipe can be expressed as

$$
\begin{aligned}
\dot{X}_{\mathrm{p}(k), \mathrm{b}}= & \boldsymbol{U}_{\mathrm{p}(k), \mathrm{b}} X_{\mathrm{p}(k), \mathrm{b}}+\boldsymbol{I}_{\mathrm{p}(k), \mathrm{b}} u_{\mathrm{p}(k), \mathrm{b}} \\
y_{\mathrm{p}(k), \mathrm{b}}= & \boldsymbol{O}_{\mathrm{p}(k), \mathrm{b}} X_{\mathrm{p}(k), \mathrm{b}}+\boldsymbol{P}_{\mathrm{p}(k), \mathrm{b}} u_{\mathrm{p}(k), \mathrm{b}} \\
& -\boldsymbol{O}_{\mathrm{p}(k), \mathrm{b}} \boldsymbol{U}_{\mathrm{p}(k), \mathrm{b}}^{-1} \vartheta_{\mathrm{p}(k), \mathrm{b}} \\
u_{\mathrm{p}(k), \mathrm{b}}= & \Pi y_{\mathrm{p}(k), \mathrm{b}}(t)
\end{aligned}
$$

where the differential term is regarded as the state variable, inlet temperature and flow are regarded as input variables, and the outlet temperature and flow are regarded as output variables.

$$
\begin{aligned}
& X_{\mathrm{p}(k), \mathrm{b}}=x_{\mathrm{p}(k), \mathrm{b}}+A_{\mathrm{p}(k), \mathrm{b}}^{-1} \vartheta_{\mathrm{p}(k), \mathrm{b}} \\
& x_{\mathrm{p}(k), \mathrm{b}}=\left[\Delta T_{\mathrm{p}(k), \text { out }}, \Delta T_{\mathrm{p}(k) \text {,shell }}\right]^{\mathrm{T}} \\
& y_{\mathrm{p}(k), \mathrm{b}}=\left[\Delta T_{\mathrm{p}(k), \text { out }}, \Delta G_{\mathrm{p}(k), \text { out }}\right]^{\mathrm{T}} \\
& u_{\mathrm{p}(k), \mathrm{b}}=\left[\Delta T_{\mathrm{p}(k), \text { in }}, \Delta G_{\mathrm{p}(k), \text { in }}\right]^{\mathrm{T}} \\
& \vartheta_{\mathrm{p}(k), \mathrm{b}}=\left[-\frac{d}{d t}\left(\Delta T_{\mathrm{p}(k), \mathrm{in}}\right), 0\right]^{\mathrm{T}} \\
& \boldsymbol{U}_{\mathrm{p}(k), \mathrm{b}}=\left[\begin{array}{ll}
\frac{X_{\mathrm{p}(k), 1}}{K_{1}} & \frac{X_{\mathrm{p}(k), 2}}{K_{1}} \\
\frac{Y_{\mathrm{p}(k), 1}}{K_{2}} & \frac{Y_{\mathrm{p}(k), 2}}{K_{2}}
\end{array}\right] ; \\
& \boldsymbol{I}_{\mathrm{p}(k), \mathrm{b}}=\left[\begin{array}{ll}
\frac{X_{\mathrm{p}(k), 3}}{K_{1}} & \frac{X_{\mathrm{p}(k), 4}}{K_{1}} \\
\frac{Y_{\mathrm{p}(k), 4}}{K_{2}} & \frac{Y_{\mathrm{p}(k), 4}}{K_{2}}
\end{array}\right] ; \\
& \boldsymbol{O}_{\mathrm{p}(k), \mathrm{b}}=\left[\begin{array}{ll}
1 & 0 \\
0 & 0
\end{array}\right] \text {; } \\
& \boldsymbol{P}_{\mathrm{p}(k), \mathrm{b}}=\left[\begin{array}{ll}
0 & 0 \\
0 & 1
\end{array}\right] ; \\
& \Pi y(t)=y(t-\tau)
\end{aligned}
$$

2.3. Valve. In pipe network, the relation between the valve opening and the water flow rate can be expressed as follows:

$$
\begin{aligned}
& N_{v}=\frac{F_{v, \text { max }}}{F_{v, \text { min }}} \\
& H_{v}=\frac{l_{v}}{l_{v, \text { max }}}
\end{aligned}
$$

The mass and energy equation can be expressed as

$$
\begin{gathered}
G_{\mathrm{v}, \text { out }}=G_{\mathrm{v}, \text { in }}=G_{\mathrm{v}} \\
T_{\mathrm{v}, \text { out }}=T_{\mathrm{v}, \text { in }}=T_{\mathrm{v}} \\
F_{\mathrm{v}}^{2} P_{\mathrm{v}, \Delta}=\frac{1}{2} \xi_{\mathrm{v}} \frac{G_{\mathrm{v}, \text { out }}^{2}}{\rho_{\mathrm{w}}}
\end{gathered}
$$

Through parameter linearization, the state-space model of valve can be expressed as

$$
\begin{aligned}
& \dot{x}_{\mathrm{v}}(t)=\text { constant } \\
& y_{\mathrm{v}}(t)=\boldsymbol{P}_{\mathrm{v}} u_{\mathrm{v}}(t)
\end{aligned}
$$

where

$$
\begin{aligned}
& y_{\mathrm{v}}=\left[y_{\mathrm{v}, \mathrm{w}}, \Delta G_{\mathrm{v}, \text { out }}\right]^{\mathrm{T}} ; \\
& y_{\mathrm{v}, \mathrm{w}}=\left[\Delta T_{\mathrm{v}, \mathrm{L}}, \Delta G_{\mathrm{v}, \text { out }}\right]^{\mathrm{T}} ; \\
& u_{\mathrm{v}}=\left[u_{\mathrm{v}, \mathrm{w}}, \Delta H_{\mathrm{v}}, \Delta P_{\mathrm{v}, \Delta}\right]^{\mathrm{T}} ; \\
& u_{\mathrm{v}, \mathrm{w}}=\left[\Delta T_{\mathrm{v}, \text { in }}, \Delta G_{\mathrm{v}, \text { in }}\right]^{\mathrm{T}} ; \\
& \boldsymbol{P}_{\mathrm{v}}=\left[\begin{array}{lll}
0 & 1 & 0 \\
0 & 0 & V_{1} \\
0 & 0 & V_{2}
\end{array}\right] \\
& V_{1}=\frac{2 \rho_{\mathrm{w}} A_{\mathrm{v}, \max }^{2} f\left(H_{\mathrm{v}}\right)_{\mathrm{s}}\left(P_{\mathrm{v}, \Delta}\right)_{\mathrm{s}}}{\xi_{\mathrm{v}}\left(G_{\mathrm{v}, \mathrm{L}}\right)_{\mathrm{s}}} \cdot \frac{\partial f\left(H_{\mathrm{v}}\right)}{\partial H_{\mathrm{v}}} ; \\
& V_{2}=\frac{\rho_{\mathrm{w}} A_{\mathrm{v}, \max }^{2} f^{2}\left(H_{\mathrm{v}}\right)_{\mathrm{s}}}{\xi_{\mathrm{v}}\left(G_{\mathrm{v}, L}\right)_{\mathrm{s}}}
\end{aligned}
$$

\section{Control Strategy for the Temperature of Water Pipe}

3.1. Design for Preview Controller. The control problem for pipes is to maintain temperature and flow at some specified set point using valve. For improving the performance of the air conditioning control system, controller is required to track the output signal and input signal closely, and the error signal between the state value and set value is often regarded as the target signal. In general, the feedback control of the traditional central air-conditioning needs the current system state and overcomes numerous external distractions. However, some future state signals and interference signals in the air conditioning system can be predicted, such as weather, planned schedule of people, pumps start or stop, and load requirement. To improve the control performance of the system, the method using future information is preview control known as linear quadratic optimal control, and Figure 3 shows the control principle. The input maintaining the pipe temperature state equals the output of the controller. Hence, based on the pipe thermal T-SII model, the control strategy is to search the optimal input signal. 


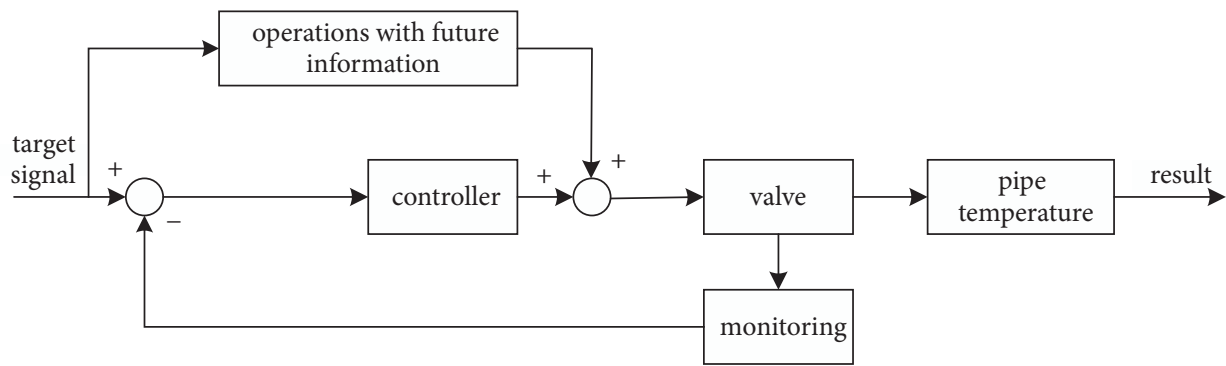

Figure 3: The preview control structure.

In order to simplify the controller designing algorithm and improve the calculation speed, T-SII model should be discretized using difference equation $(\Delta x(k)=x(k)-x(k-1))$. In this process, it is assumed that the system is sampled by an equal interval. When $t=k \mathrm{~T}$, the sample values will change. In (11), $\vartheta_{\mathrm{p}}$ is a minimal variable; therefore it can be neglected. Then, the discretization is defined

$$
\begin{aligned}
\dot{x}(k+1) & =\overrightarrow{\boldsymbol{U}}_{\mathrm{p}} x(k)+\overrightarrow{\boldsymbol{I}}_{\mathrm{p}} u(k) \\
y(k) & =\overrightarrow{\boldsymbol{O}}_{\mathrm{p}} x(k)+\overrightarrow{\boldsymbol{P}}_{\mathrm{p}} u(k) \\
u(k) & =u(k-\tau)
\end{aligned}
$$

where $k$ is sampling value $(1,2, . ., N)$. The parameter of temperature or flow changes periodically, and the preview length is $M_{\mathrm{R}}$. The error signal is

$$
e(k)=R(k)-y(k)
$$

where $R(k)$ is the target signal. The first-order differential for $x(k+1)$ is

$$
\begin{aligned}
\Delta x(k+1)= & \overrightarrow{\boldsymbol{U}}_{p}(k) \Delta x(k)+\Delta \overrightarrow{\boldsymbol{U}}_{p}(k) x(k-1) \\
& +\overrightarrow{\boldsymbol{I}}_{p}(k) \Delta u(k)+\Delta \overrightarrow{\boldsymbol{I}}_{p}(k) u(k-1) \\
& +\overrightarrow{\boldsymbol{I}}_{1}(k) \Delta u(k-\tau) \\
& +\Delta \overrightarrow{\boldsymbol{I}}_{1}(k) u(k-\tau-1)
\end{aligned}
$$

The error signal $(e(\mathrm{k}+1))$ is

$$
e(k+1)=R(k+1)-y(k+1)
$$

Then,

$$
\begin{aligned}
\Delta e(k+1)= & \Delta R(k+1)-\Delta y(k+1) \\
= & \Delta R(k+1)-\Delta\left[\overrightarrow{\boldsymbol{O}}_{p}(k+1) x(k+1)\right] \\
= & \Delta R(k+1)-\overrightarrow{\boldsymbol{O}}_{p}(k+1) \Delta x(k+1) \\
& -\Delta \overrightarrow{\boldsymbol{O}}_{p}(k+1) x(k) \\
e(k+1)= & e(k)+\Delta e(k+1)
\end{aligned}
$$

Thus, the error system is defined as follows:

$$
\begin{aligned}
\widehat{\boldsymbol{X}}(k+1)= & \boldsymbol{H}_{1}(k) \widehat{X}(k)+\boldsymbol{H}_{2}(k) \Delta u(k) \\
& +\boldsymbol{H}_{3}(k) \Delta u(k-\tau) \\
& +\boldsymbol{H}_{4}(k) u(k-\tau-1) \\
& +\boldsymbol{H}_{5}(k) \Delta \boldsymbol{R}(k+1)
\end{aligned}
$$

$$
\begin{aligned}
\boldsymbol{H}_{1}(k) & =\left[\begin{array}{cccc}
I-\Delta \overrightarrow{\boldsymbol{O}}_{p}(k+1)-\overrightarrow{\boldsymbol{O}}_{p}(k+1) \overrightarrow{\boldsymbol{U}}_{p}(k) & -\Delta \overrightarrow{\boldsymbol{O}}_{p}(k+1)-\overrightarrow{\boldsymbol{O}}_{p}(k+1) \Delta \overrightarrow{\boldsymbol{U}}_{p}(k) & -\overrightarrow{\boldsymbol{O}}_{p}(k+1) \overrightarrow{\boldsymbol{I}}_{p}(k) \\
0 & \overrightarrow{\boldsymbol{U}}_{p}(k) & \Delta \overrightarrow{\boldsymbol{U}}_{p}(k) & \Delta \overrightarrow{\boldsymbol{I}}_{\boldsymbol{p}}(k) \\
0 & \boldsymbol{E} & \boldsymbol{E} & 0 \\
\boldsymbol{H}_{2}(k) & =\left[\begin{array}{c}
-\overrightarrow{\boldsymbol{O}}_{p}(k+1) \overrightarrow{\boldsymbol{I}}_{p}(k) \\
\overrightarrow{\boldsymbol{U}}_{p}(k) \\
0 \\
\boldsymbol{E}
\end{array}\right],
\end{array}\right]
\end{aligned}
$$

where 


$$
\begin{aligned}
& \boldsymbol{H}_{3}(k)=\left[\begin{array}{c}
-\overrightarrow{\boldsymbol{O}}_{p}(k+1) \overrightarrow{\boldsymbol{I}}_{p}(k) \\
\Delta \overrightarrow{\boldsymbol{U}}_{p}(k) \\
0 \\
0
\end{array}\right] \\
& \boldsymbol{H}_{4}(k)=\left[\begin{array}{c}
-\overrightarrow{\boldsymbol{O}}_{p}(k+1) \overrightarrow{\boldsymbol{I}}_{p}(k) \\
\overrightarrow{\boldsymbol{I}}_{p}(k) \\
0 \\
0
\end{array}\right], \\
& \boldsymbol{H}_{5}(k)=\left[\begin{array}{c}
\boldsymbol{E} \\
0 \\
0 \\
0
\end{array}\right] \\
& \widehat{\boldsymbol{X}}(k)=\left[\begin{array}{ll}
e^{T}(k) & \left.\Delta x^{T}(k) x^{T}(k-1) u^{T}(k-1)\right]^{T}
\end{array}\right.
\end{aligned}
$$

The performance index function is defined as [18]

$$
J=\frac{1}{2} \sum_{k=1}^{N}\left[\widehat{\boldsymbol{X}}^{T}(k) \mathbf{Q} \widehat{\boldsymbol{X}}(k)+\Delta u^{T}(k) \boldsymbol{M} \Delta u(k)\right]
$$

where $J \leqslant J^{*}$ (the maximum value of performance index function)

$$
\begin{aligned}
& J^{*}=\tilde{x}(0)^{T} P \tilde{x}(0) ; \\
& \mathbf{Q}=\left[\begin{array}{lll}
\mathbf{Q}_{1} & & \\
& 0 & \\
& & 0
\end{array}\right] ; \quad \mathbf{Q}_{1} \in R^{m \times m} ; \\
& \boldsymbol{M} \in R^{r \times r}
\end{aligned}
$$

Through a series of transformations, the optimal preview control is changed into the optimal control of error system with the performance index ' $J$ ', and the control variable is $\Delta u(\mathrm{k})$. The minimum performance index function of the optimal control for air conditioning system pipe is

$$
\begin{aligned}
\Delta u(k)= & -\left[\boldsymbol{M}+\boldsymbol{G}^{T}(k) \boldsymbol{P}(k+1) \boldsymbol{G}(k)\right]^{-1} \boldsymbol{G}^{T}(k) \\
& \cdot \boldsymbol{P}(k+1) \boldsymbol{H}(k) X_{0}(K)
\end{aligned}
$$

where

$$
\begin{aligned}
& \boldsymbol{G}(\boldsymbol{k})=\left[\begin{array}{c}
\widehat{\boldsymbol{G}}(\boldsymbol{k}) \\
0
\end{array}\right] \\
& \widehat{\boldsymbol{G}}(\boldsymbol{k})=\left[\begin{array}{c}
\widetilde{\boldsymbol{G}}(\boldsymbol{k}) \\
I
\end{array}\right] \text {; } \\
& \widetilde{\boldsymbol{G}}(\boldsymbol{k})=\left[\begin{array}{c}
\boldsymbol{H}_{\mathbf{4}} \\
0
\end{array}\right] \\
& \boldsymbol{P}(k)=\left[\begin{array}{cc}
\boldsymbol{P}_{11}(k) & \boldsymbol{P}_{12}(k) \\
\boldsymbol{P}_{12}^{T}(k) & \boldsymbol{E}
\end{array}\right] \\
& \boldsymbol{P}_{11}(k)=\mathbf{Q}+\boldsymbol{H}_{1}^{T}(k) \boldsymbol{P}_{11}(k+1) \boldsymbol{H}_{1}(k)-\boldsymbol{H}_{1}^{T}(k) \\
& \cdot \boldsymbol{P}_{11}(k+1) \boldsymbol{H}_{2}(k)\left[\boldsymbol{M}+\boldsymbol{H}_{2}^{T}(k) \boldsymbol{P}_{11}(k+1)\right. \\
& \left.\cdot \boldsymbol{H}_{2}(k)\right]^{-1} \boldsymbol{H}_{2}^{T}(k) \boldsymbol{P}_{11}(k+1) \boldsymbol{H}_{1}(k) \\
& \boldsymbol{P}_{12}(k)=\boldsymbol{H}_{1}^{T}(k)\left\{\boldsymbol{I}-\boldsymbol{P}_{11}(k+1) \boldsymbol{H}_{2}(k)\right. \\
& \left.\cdot\left[\boldsymbol{M}+\boldsymbol{H}_{2}^{T}(k) \boldsymbol{P}_{11}(k+1) \boldsymbol{H}_{2}(k)\right]^{-1} \boldsymbol{H}_{2}^{T}(k)\right\} \\
& \cdot\left[\boldsymbol{P}_{11}(k+1)+\boldsymbol{P}_{12}(k+1)\right]
\end{aligned}
$$

3.2. Robustness Performance. Robust stability refers to the ability of remaining stable for control system [19]. In other words, the preview controller should track the target signal $R(k)$ with no steady-state error in spite of being affected by 
an uncertain disturbance, and the relationship between $y(\mathrm{k})$ and $r(k)$ is

$$
\lim _{k \rightarrow \infty} e(k)=\lim _{k \longrightarrow \infty}(y(k)-R(k))=0
$$

For any given invertible matrix $\widehat{\mathbf{X}}$, the operator $\Delta$ : $y(k) \longrightarrow R(k)$ enjoys the property $\left\|\widehat{\mathbf{X}} \Delta \widehat{\mathbf{X}}^{-1}\right\|_{\infty} \leq 1$, and the robustly asymptotically stable of system (26) with the constraint $(J)$ can be proved according to the lemmas in [20]. Meanwhile, the state feedback for system (20) will be defined

$$
u(k)=K \Delta u(k)
$$

Therefore, the robustness is determined by the gain matrix $(K)$ which can be solved by LMI. It means that the optimization problem has an optimal solution with constraint, and the following condition can be derived according to the principles introduced using the result in [21]:

$$
\begin{aligned}
u(k)= & K \Delta u(k) \\
= & k_{e} e(k)+k_{x} x(k)+\sum_{i=0}^{M_{R}} k_{R}(i) R(k+i) \\
& +k_{V} \sum_{s=0}^{k-1} e(s)
\end{aligned}
$$

where

$$
K=\left[\begin{array}{llll}
k_{e} & k_{x} & k_{R} & k_{V}
\end{array}\right]
$$

\section{Experimental Setup}

In this work, data is registered in a fan-coil system, which is installed in Southwest Jiaotong University. Figure 4(a) shows the schematic diagram, illustrating that this system employs an air source heat pump with a rated power of $2200 \mathrm{~W}$, and two fan-coil units (FCU) with an air flow rate of $1020 \mathrm{~m}^{3} / \mathrm{h}$. Temperature sensors (precision: 0.005) have been installed in the inlet and outlet of pipes and fan-coil units. The chilled water supply pipes of test platform are divided into 10 pipes according to the division of the flow, and return pipes are divided into 6 pipes, as shown in Figures 4(b) and 4(c). The details of the equipment, materials, and pipe size are shown in Table 1 . The valves (DN:25, turning force:30N) and pumps (circulating pump head:25m, chilled pump head:22m) are included in the necessary peripheral equipment. Programmable logic controller is served as the main control equipment, which employs preview control algorithm. Installed in the computer outside the experiment room, the monitoring platform is designed by utilizing Siemens WinCC. Meanwhile, two experiment rooms with the same volume of $46.6 \mathrm{~m}^{3}$ and the exterior-protected construction with the cystosepiment (thickness of $150 \mathrm{~mm}$ ) are chosen in this paper. Besides, data acquisition unit with 44 channels is chosen as the performance analysis source for the T-SII model.

To begin with, the specific parameters shown in Table 2 need to be determined through experiments.
According to (11) and (18), the coefficient matrix in system (20) can be expressed as

$$
\begin{aligned}
& \overrightarrow{\boldsymbol{U}}_{P}=\left[\begin{array}{cccc}
-0.3659 & 0.1801 & 0 & 0 \\
0.4927 & -0.1117 & 0 & 0 \\
0 & 0 & -1.7838 & 0.1975 \\
0 & 0 & 0.5913 & -0.1253
\end{array}\right] \\
& \overrightarrow{\boldsymbol{I}}_{P}=\left[\begin{array}{cccc}
0.4287 & -1.6332 & 0 & 0 \\
0.4927 & -0.8115 & 0 & 0 \\
0 & 0 & 0.1823 & -0.1046 \\
0 & 0 & 0.5913 & -0.6332
\end{array}\right] \\
& \overrightarrow{\boldsymbol{O}}_{P}=\left[\begin{array}{cccc}
-0.5641 & 0.3040 & 0 & 0 \\
0.1870 & -0.3906 & 0 & 0 \\
0 & 0 & -0.3794 & 0.2888 \\
0 & 0 & 0.1776 & -0.3648
\end{array}\right] \\
& \overrightarrow{\boldsymbol{P}}_{P}=\left[\begin{array}{ccc}
1 & 0 & 0 \\
0 & 1 & 0 \\
0 & 0 & 1.8576 \\
0 & 0 & 6.5917
\end{array}\right]
\end{aligned}
$$

In this work, the simulation system for models and preview control strategies is set up using TRNSYS (Transient System Simulation Program) and MATLAB. The models are validated against actual data gathered from actual experimental plant, and the performance analysis of preview control strategies is validated in the simulation system. Figure 5 shows the simulation diagram of this experiment.

\section{Results and Discussions}

5.1. Experimental Results. The mean squared error (MSE) is used to evaluate the model accuracy by comparing the calculated results with the experimental data during the transient response process, which is defined

$$
\mathrm{MSE}=\frac{1}{n} \sum_{i=1}^{n} E_{i}^{2}=\frac{1}{n} \sum_{i=1}^{n}\left(y_{i}-y_{i}^{d}\right)^{2}
$$

where $y$ is the difference between the response parameters and the initial value, the subscript ' $i$ ' is the output value of the T-SII model, and $\mathrm{n}$ is sampling point total number, $n=50$. The superscript ' $d$ ' is the value acquiring from the actual data. The initial conditions, which are necessary for model simulation, are measured under the steady conditions before perturbations beginning to be applied in pipe system. The actual measured data are compared with the output of the T-SII model for the pipes temperature of room_1 and room_2 in summer and winter conditions. Figures 6, 7, 8, and 9 show the comparison between the measured value and predicted value of the simulation system in the inlet of the chilled water supply and return pipe for room_1 and room_2 separately. Results show that the T-SII model has 


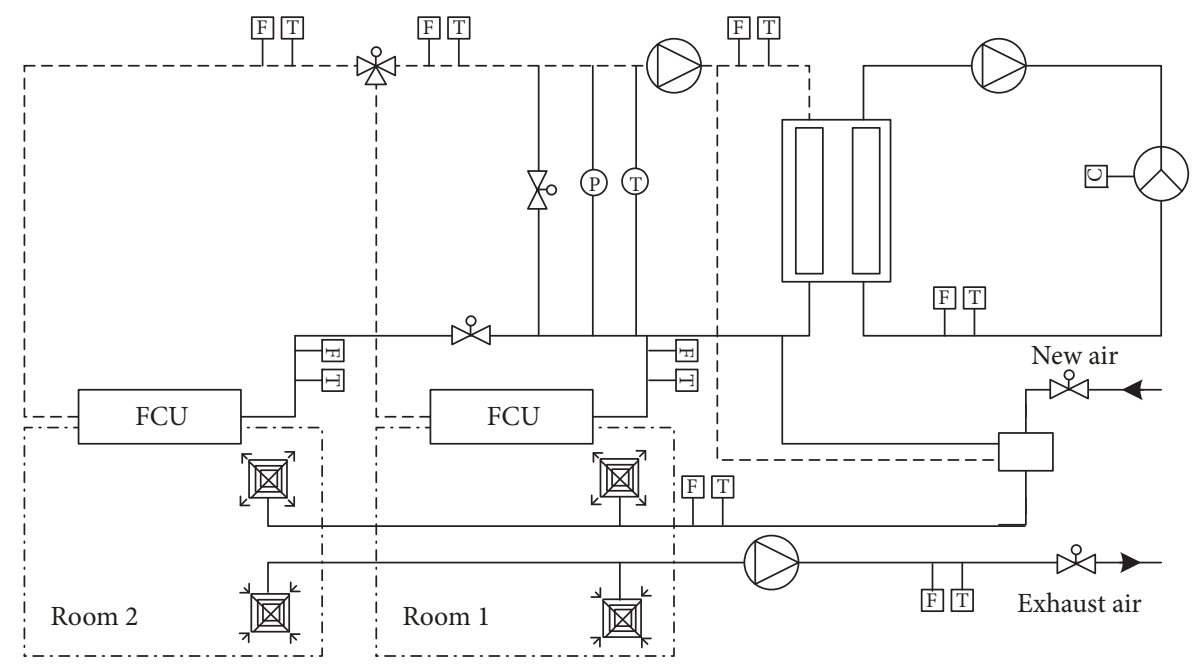

(a)

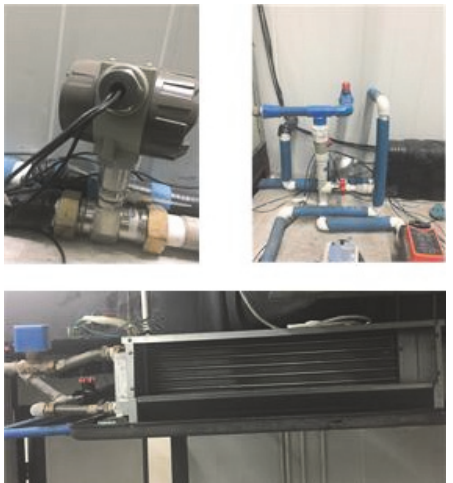

(b)

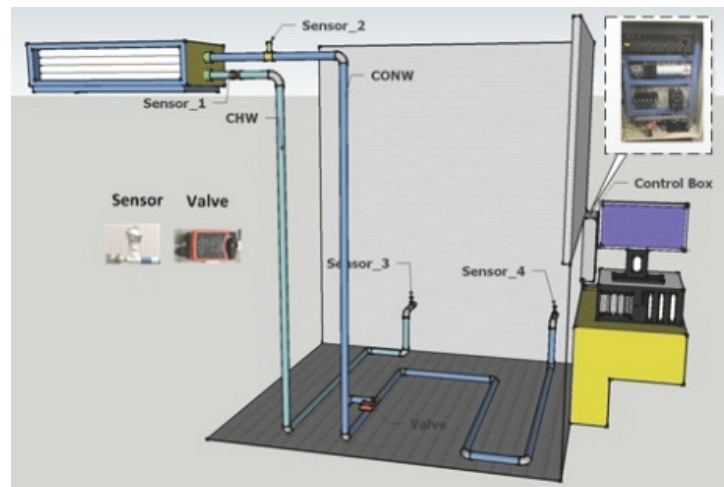

(c)

FIGURE 4: Schematic diagram of the experiment house. (a) Schematic diagram of chilled water loop; (b) experimental equipment; (c) the layout of room_1.

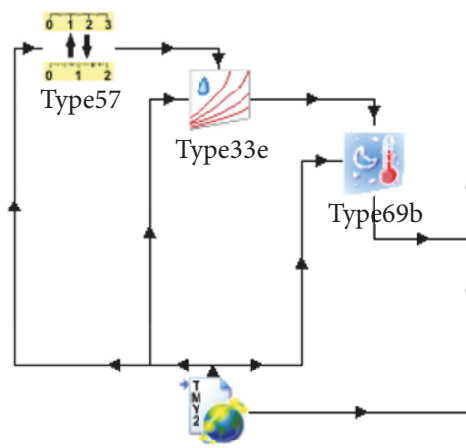

Type109-TMY2
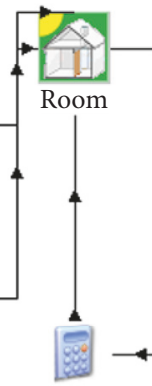

T\&F supply-1
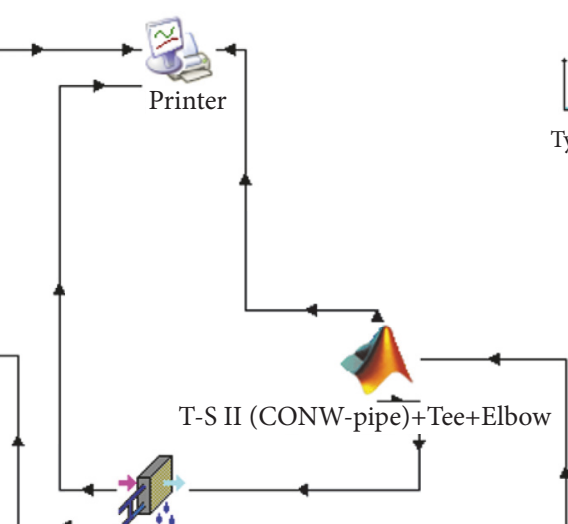

Coolingcoil-1

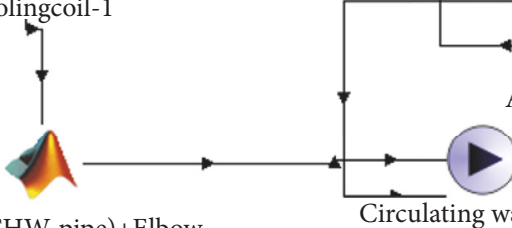

T-S II (CHW-pipe)+Elbow

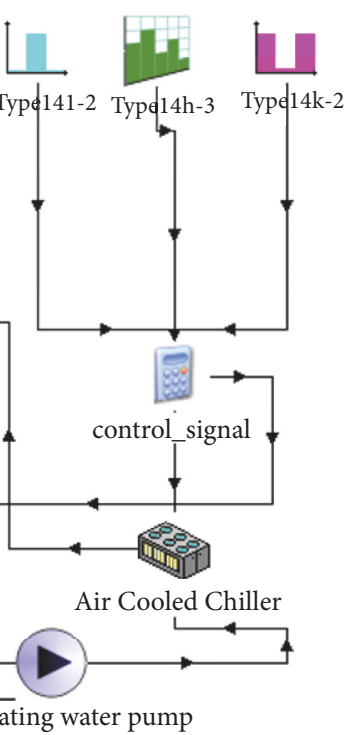

FIgURE 5: The simulation of this experiment using MATLAB and TRNSYS. 
TABLE 1: Structural information of equipment.

\begin{tabular}{lcc}
\hline & & Pipe \\
\hline Material & CONW & PPR \\
Size & PPR & DN: $20 \mathrm{~mm}$ \\
No.1 & DN: $20 \mathrm{~mm}$ & $150 \mathrm{~mm}$ \\
No.2 & $500 \mathrm{~mm}$ & $1670 \mathrm{~mm}$ \\
No.3 & $350 \mathrm{~mm}$ & $900 \mathrm{~mm}$ \\
No.4 & $900 \mathrm{~mm}$ & $300 \mathrm{~mm}$ \\
No.5 & $350 \mathrm{~mm}$ & $350 \mathrm{~mm}$ \\
No.6 & $600 \mathrm{~mm}$ & $500 \mathrm{~mm}$ \\
No.7 & $500 \mathrm{~mm}$ & -- \\
No.8 & $360 \mathrm{~mm}$ & -- \\
No.9 & $140 \mathrm{~mm}$ & -- \\
No.10 & $1750 \mathrm{~mm}$ & -- \\
\hline
\end{tabular}

Remarks: electronic valve (DN: $25 \mathrm{~mm}$ ), insulating layer (thickness: $5 \mathrm{~mm}$ ).

TABLE 2: Summarized initial parameter of the experimental system.

\begin{tabular}{lcr}
\hline$\left(T_{\mathrm{iw}}\right)_{\mathrm{s}}$ & $\left(T_{\mathrm{ow}}\right)_{\mathrm{s}}$ & $\left(T_{\mathrm{ps}}\right)_{\mathrm{s}}$ \\
$23.2^{\circ} \mathrm{C}$ & $22.8{ }^{\circ} \mathrm{C}$ & $24.4{ }^{\circ} \mathrm{C}$ \\
$\left(G_{\mathrm{p}}\right)_{\mathrm{s}}$ & $\rho_{\mathrm{p}}$ & $c_{\mathrm{p}}$ \\
$0.205 \mathrm{~kg} / \mathrm{s}$ & $0.91 \mathrm{~g} / \mathrm{cm}^{3}$ & $4.2 \mathrm{~kJ} /\left(\mathrm{kg} \cdot{ }^{\circ} \mathrm{C}\right)$ \\
$\lambda_{\mathrm{i} 1}$ & $h_{\mathrm{il}}$ & $\rho_{\mathrm{w}}$ \\
$0.034 \mathrm{~W} / \mathrm{m} \cdot \mathrm{K}$ & $9.5 \mathrm{~W} /\left(\mathrm{m}^{2} \cdot \mathrm{K}\right)$ & $0.997 \mathrm{~g} / \mathrm{m}^{3}$ \\
\hline
\end{tabular}

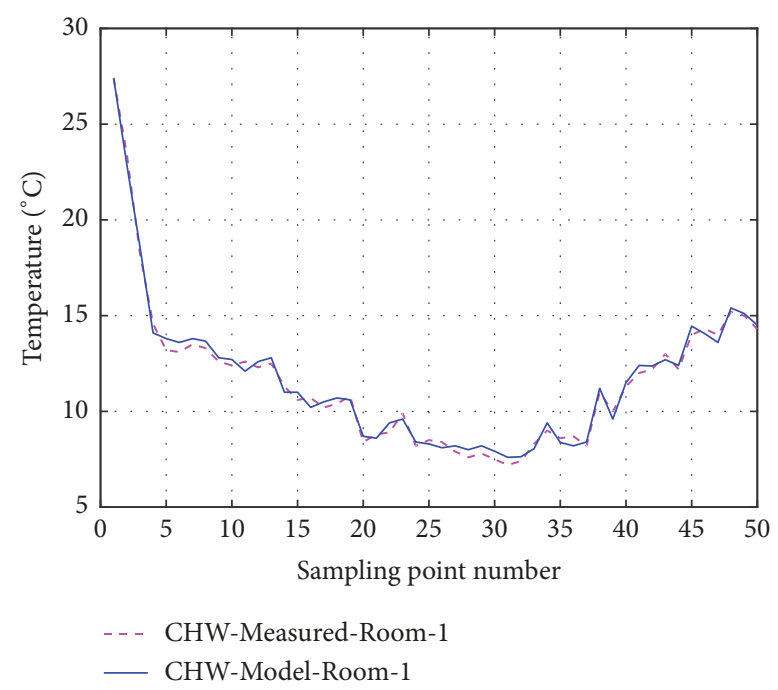

FIGURE 6: Comparison of measured value and predicted value of the simulation system for CHW temperature in room_1.

better prediction performance, and the prediction data of the model is close to the measured data. According to (38), the average MSE of the chilled supply water temperature and chilled water return temperature in room_1 and room_2 are $11.14 \%$ and $12.82 \%$, respectively, which indicates that the TSII model developed in this paper is capable of predicting the performance of the water thermal variation satisfactorily. Considering the results, T-SII model can apply to other equipment and system with the different initial values, and

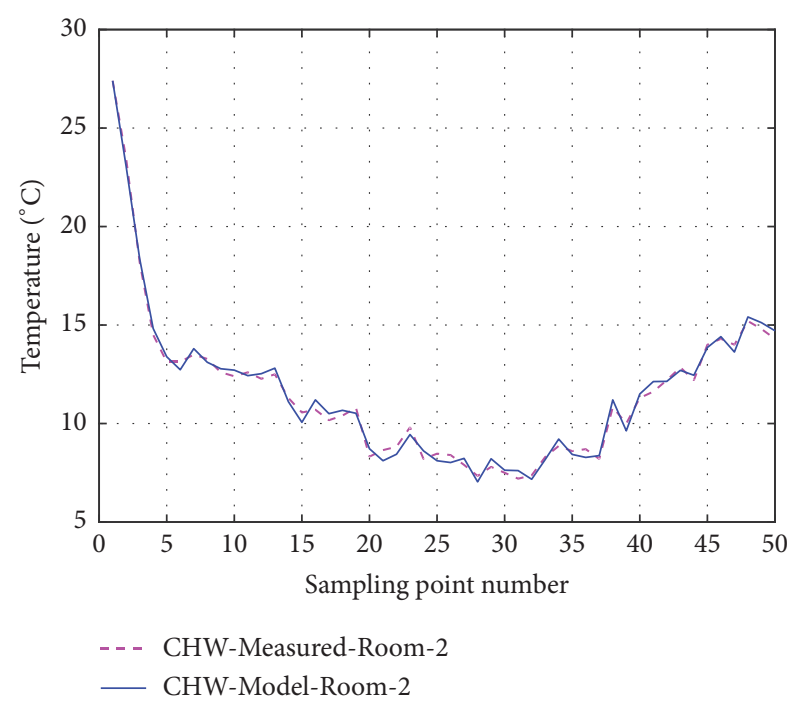

FIGURE 7: Comparison of measured value and predicted value of the simulation system for CHW temperature in room_2.

the process of establishing T-SII model is relatively simple. However, time delay is one of the influence factors in ACWS; other nonlinear phenomena should be considered in further researching.

5.2. Simulation Results. The important functional coefficients in preview control are gain matrix $(K)$ and preview lengths 


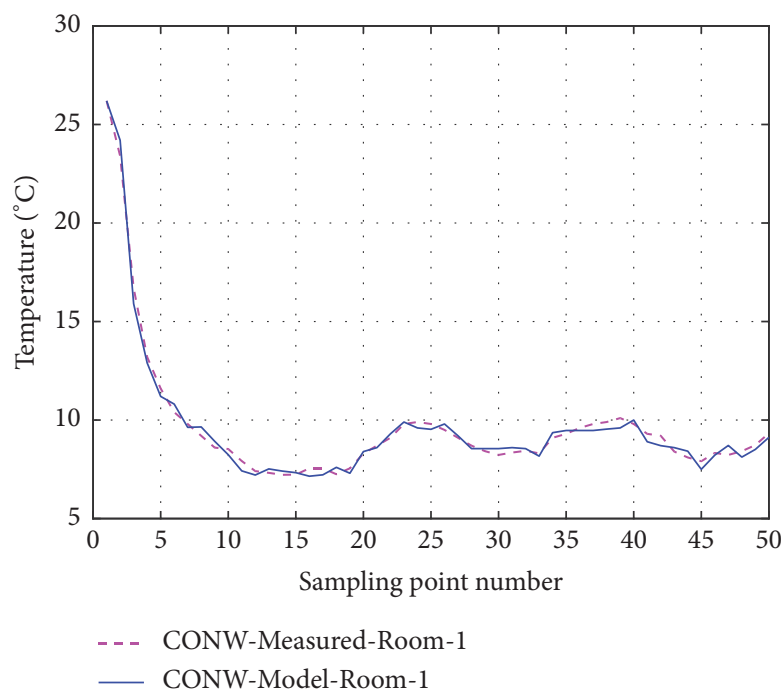

Figure 8: Comparison of measured value and predicted value of the simulation system for CONW temperature in room_1.

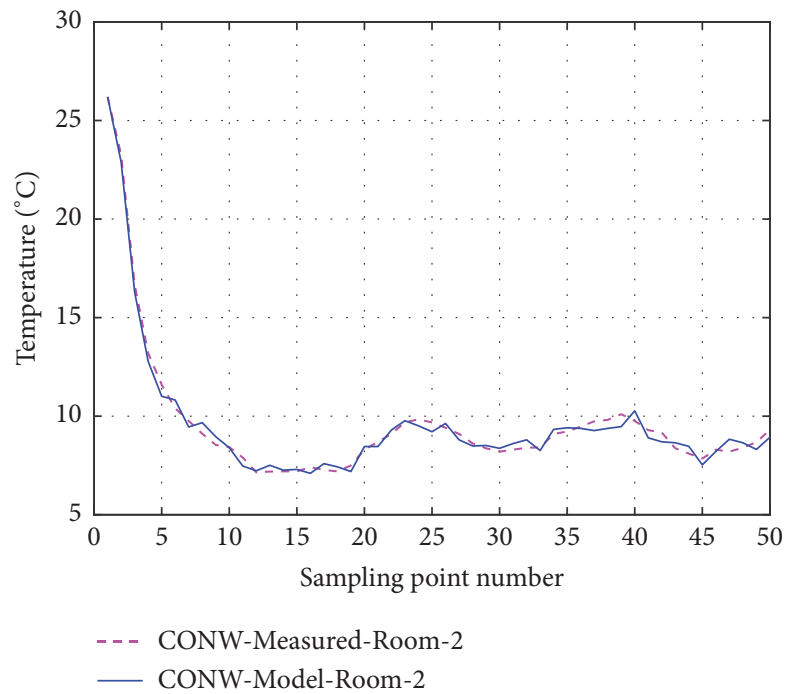

FIGURE 9: Comparison of measured value and predicted value of the simulation system for CONW temperature in room_2.

$\left(M_{\mathrm{R}}\right)$. Expediently, the LMI toolbox of MATLAB is used to determine the gain matrix of preview controller [22], and three situations $\left(M_{\mathrm{R}}=0 ; M_{\mathrm{R}}=10 ; M_{\mathrm{R}}=20\right)$ are discussed to obtain the optimal coefficient for this experiment. In this simulation, the based coefficient matrix of T-SII model is shown in (37), and the reference signal is the regulating variable of temperature, and it can be taken as a step signal:

$$
R(k)= \begin{cases}0 & k<\tau \\ T & k \geq \tau\end{cases}
$$

where $T$ is the regulating variable of temperature, ${ }^{\circ} \mathrm{C}$. When $T=1^{\circ} \mathrm{C}, \tau=30$,

$$
\begin{aligned}
& M_{\mathrm{R}}=0 \text {, } \\
& K=\left[\begin{array}{lll}
k_{e} & k_{x} & k_{V}
\end{array}\right] \\
& =\left[\begin{array}{lllll}
-0.4643 & -0.3582 & -6.5162 & -2.4628 & -1.6459
\end{array}\right] \\
& M_{\mathrm{R}}=10, \\
& k_{e}=-0.4758 ; \\
& k_{x}=\left[\begin{array}{lll}
-0.3221 & -6.7463 & -2.3584
\end{array}\right] \text {; } \\
& k_{R}=\left[\begin{array}{llll}
-1.7315 & -0.4326 & -0.4326 & -0.4326
\end{array}\right] \text {; } \\
& k_{V}=-1.6574 \\
& M_{\mathrm{R}}=20 \text {, } \\
& k_{e}=-0.4258 ; \\
& k_{x}=\left[\begin{array}{lll}
-0.4154 & -6.3641 & -2.6774
\end{array}\right] ; \\
& k_{R}=\left[\begin{array}{llll}
-1.3527 & -0.4106 & -0.4106 & -0.4106
\end{array}\right] \text {; } \\
& k_{V}=-1.4261
\end{aligned}
$$

Further, investigation will be taken to study the effect of three preview lengths of the reference signal on the closed-loop system. In this simulation, Figure 10 shows the output response of the closed-loop system when regulating variable is $1^{\circ} \mathrm{C}$, and the tracking error is reduced and the settling time can be shortened. Moreover, by increasing the preview length of the reference signal, the output can track the reference signal faster. For analyzing the robustness and stability with preview control, the output response in different regulating variable and interference is discussed. Figure 11 shows the output response of pipe temperature in different regulating variable which represents various operating conditions including start and stable. It can be seen that the temperature response is asymptotically stable under any regulating variable and meets the control requirements. The parameters of the system may change during operation due to the interference. Figure 12 shows the output response of pipe temperature with different temperature interference, when the regulating variable is $1^{\circ} \mathrm{C}$. It can be proved that system with preview control is robust stability.

According to the simulation result of TRNSYS and MATLAB, Figure 13 shows the response curve between valve opening target signal and tracking signal with the controller in which the preview feed forward compensation is not considered. It can be seen that the output signal cannot immediately trace the target signal with the variation of the valve-opening target signal. Although there is a time delay and deviation, it can trace the target signal later. Figure 14 shows the response curve when controller adopts the preview feed forward compensation. In this condition, the valve opening target signal can be promptly traced using the coefficients in (42). Meanwhile, the time delay does not appear and the error is minor in comparison with no preview control. Therefore, the tracking performance is improved, and the effect of time delay can be reduced. 


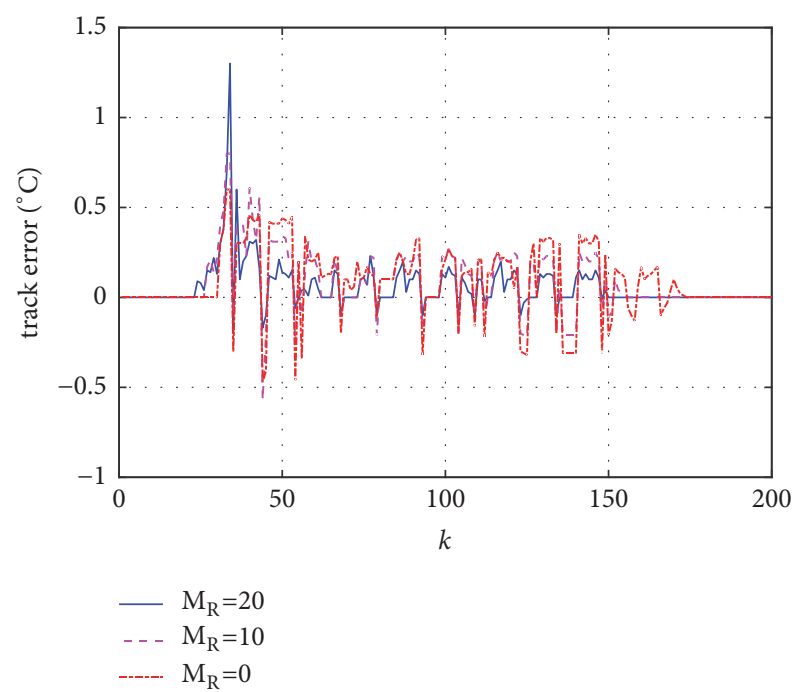

FIGURE 10: Comparison of tracking error for simulation system with different preview lengths.

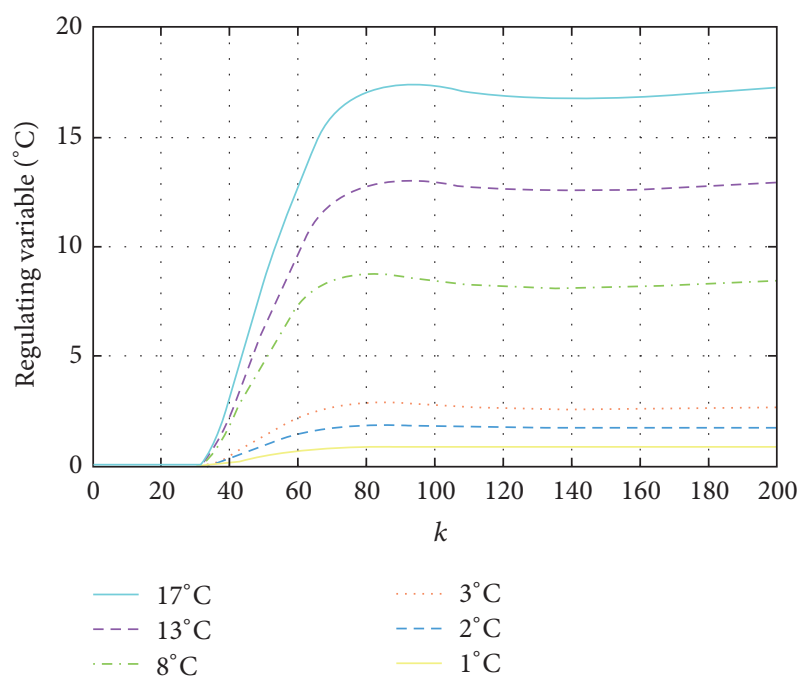

FIGURE 11: Comparison of output response for pipe temperature with different regulating variables.

\section{Conclusions}

The main goal of this study is to design the simplified thermal time-delay state-space model (T-SII model) and preview control for chilled water system in air-conditioning system. T-SII model adopted small increments as model state variables in order to fully reflect the thermal variation process, and preview control which behaves robustness and stability was applied based on the T-SII model. The results of experiment showed that T-SII model is capable of predicting the performance of the water thermal variation satisfactorily, and the delay time has been compensated by the preview control. Meanwhile, the results of simulation showed that the output of the preview control can track the reference signal faster by increasing the preview length of the reference signal, and the system with this control was robust stability. And also, the tracking performance has been improved in comparison with no preview control.

\section{Nomenclature}

$\tau: \quad$ Time delay, $\mathrm{s}$

c: $\quad$ Mass specific heat, $\mathrm{J} / \mathrm{kg}^{\circ} \mathrm{C}$

T: $\quad$ Temperature, ${ }^{\circ} \mathrm{C}$

$t: \quad$ Time, $\mathrm{s}$

$L: \quad$ The pipe length, $\mathrm{m}$

$\rho: \quad$ Density, $\mathrm{kg} / \mathrm{m}^{3}$

F: $\quad$ Area, $\mathrm{m}^{2}$

$G$ : $\quad$ Mass flow rate of water, $\mathrm{kg} / \mathrm{s}$

$h$ : Coefficient of convection heat transfer, $\mathrm{W} /\left(\mathrm{m}^{2 \circ} \mathrm{C}\right)$

M: $\quad$ Mass, $\mathrm{kg}$

$R: \quad$ Thermal resistance, ${ }^{\circ} \mathrm{C} / \mathrm{W}$

$\beta$ : $\quad$ Additional coefficient

$\sigma: \quad$ Coefficient of convection, $\mathrm{W} /\left(\mathrm{m}^{2 \circ} \mathrm{C}\right)$

$\mu: \quad$ Thermal conductivity, $\mathrm{W} / \mathrm{m}$

N: $\quad$ Turndown ratio of valve, $\%$

$H$ : $\quad$ Relative opening degree of valve, \%

$\xi: \quad$ Local resistance coefficient

$P: \quad$ pressure, $\mathrm{Pa}$

E: $\quad$ Unit matrix

LMI: Linear Matrix Inequation

CHW: Return water pipe

CONW: Supply water pipe.

\section{Subscripts}

$\begin{array}{ll}\text { env: } & \text { Environment } \\ \text { pl: } & \text { Pure lag }\end{array}$

$p$ and $p(k)$ : Pipe and pipe number

$w: \quad$ Water

$v: \quad$ Valve

$i w$ : Inlet water temperature

ow: $\quad$ Outlet water temperature

ps: $\quad$ Pipe surface

il: $\quad$ Insulation layer

ps: $\quad$ Pipe shell.

\section{Data Availability}

The data used to support the findings of this study are available from the corresponding author upon request.

\section{Conflicts of Interest}

The authors declare that there are no conflicts of interest regarding the publication of this paper.

\section{Acknowledgments}

This research was conducted with financial support from the National Natural Science Foundation of China (No. 51708453) and the Team Research Project of Youth 


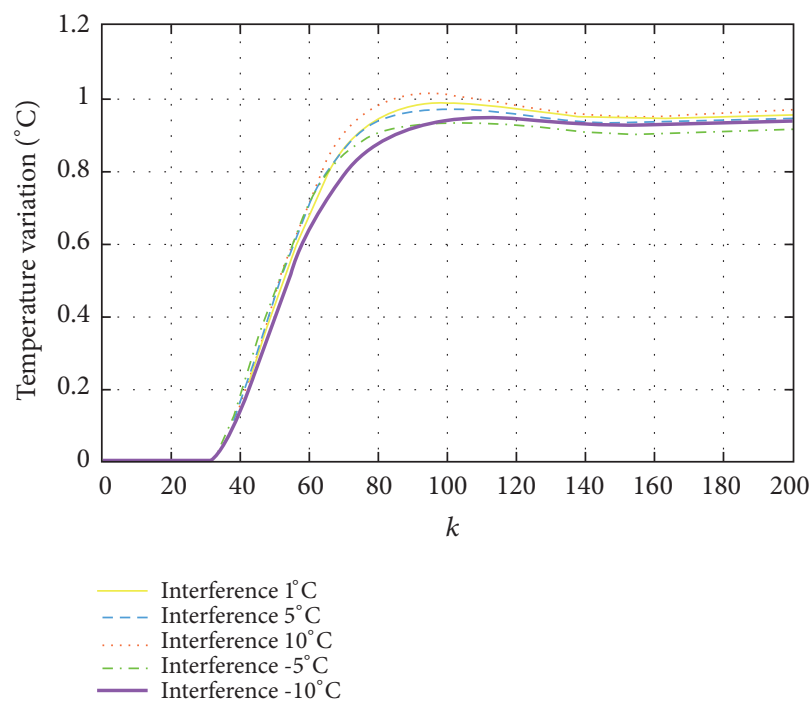

FIGURE 12: Comparison of output response for pipe temperature with different temperature interferences.

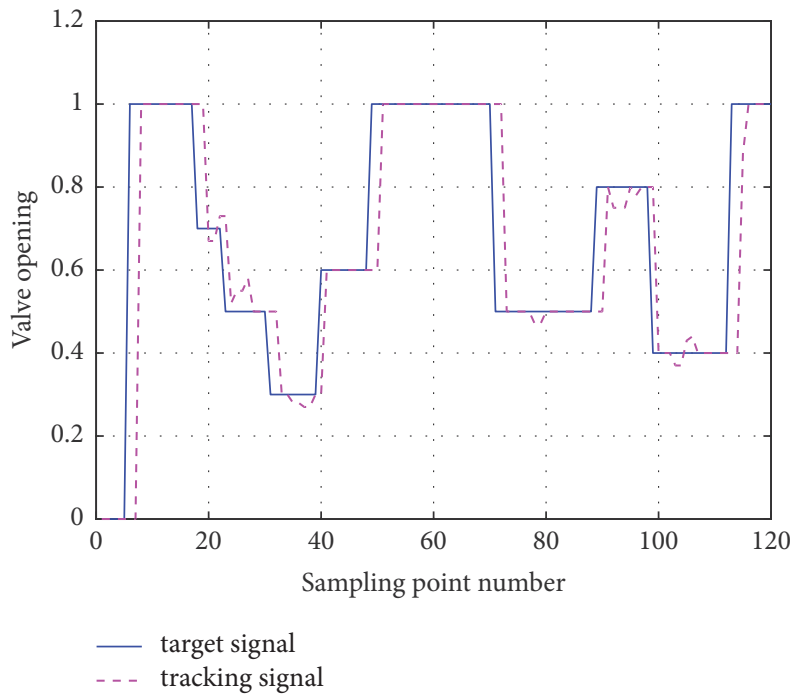

FIGURE 13: The output responses to the valve control signal without preview control.

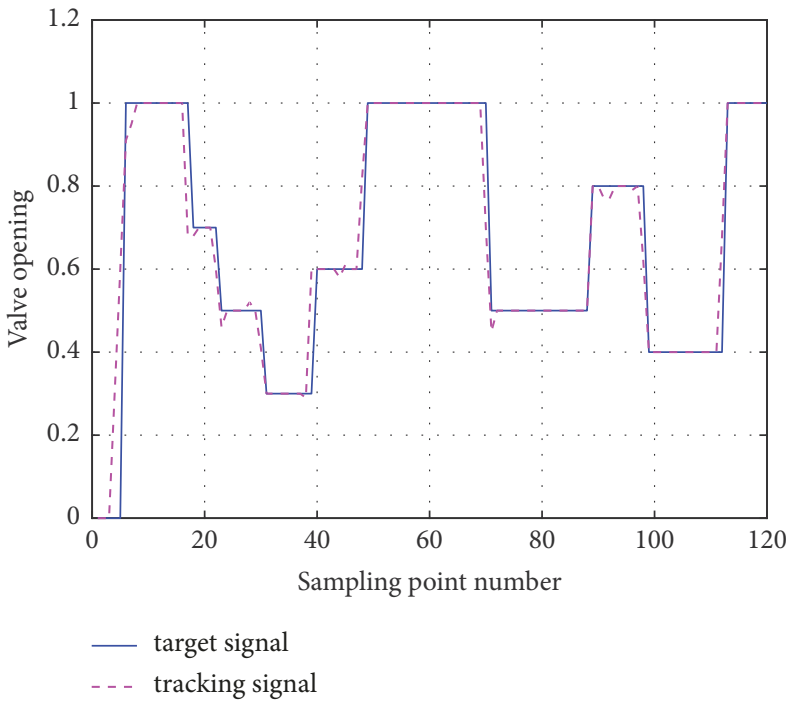

FIGURE 14: The output responses to the valve control signal with preview control. 
Science and Technological Innovation, Sichuan, China (2015TD0015).

\section{Supplementary Materials}

The correlation data used to support the findings of this study are included within the supplementary information file, including the data statistics for water temperature of $\mathrm{CHW}$ Room-1/2, CHW-Model-Room-1/2, CONW-Room-1/2, and CONW-Model-Room-1/2, respectively. (Supplementary Materials)

\section{References}

[1] T. Hibiki and T. Ozaki, "Modeling of void fraction covariance and relative velocity covariance for upward boiling flow in vertical pipe," International Journal of Heat and Mass Transfer, vol. 112, pp. 620-629, 2017.

[2] H. M. Schnedel and G. Kessel, "The DC-Equivlent circuit of fluidic line branchings," Fluidics Quarterly, vol. 15, pp. 138-145, 1972.

[3] A. Kumar, J. B. Joshi, A. K. Nayak, and P. K. Vijayan, "3D CFD simulations of air cooled condenser-III: thermal-hydraulic characteristics and design optimization under forced convection conditions," International Journal of Heat and Mass Transfer, vol. 93, pp. 1227-1247, 2016.

[4] B. van der Heijde, A. Aertgeerts, and L. Helsen, "Modelling steady-state thermal behaviour of double thermal network pipes," International Journal of Thermal Sciences, vol. 117, pp. 316-327, 2017.

[5] A. Thosar, A. Patra, and S. Bhattacharyya, "Feedback linearization based control of a variable air volume air conditioning system for cooling applications," ISA Transactions ${ }^{\circledR}$, vol. 47, no. 3, pp. 339-349, 2008.

[6] Y. Yao, M. Huang, and J. Chen, "State-space model for dynamic behavior of vapor compression liquid chiller," International Journal of Refrigeration, vol. 36, no. 8, pp. 2128-2147, 2013.

[7] Y. Yao, W. Wang, and M. Huang, "A state-space dynamic model for vapor compression refrigeration system based on movingboundary formulation," International Journal of Refrigeration, vol. 60, pp. 174-189, 2015.

[8] F. Ding, X. Liu, and Y. Gu, "An auxiliary model based least squares algorithm for a dual-rate state space system with timedelay using the data filtering," Journal of The Franklin Institute, vol. 353, no. 2, pp. 398-408, 2016.

[9] Y. Gu and F. Ding, "Auxiliary model based least squares identification method for a state space model with a unit time-delay," Applied Mathematical Modelling: Simulation and Computation for Engineering and Environmental Systems, vol. 36, no. 12, pp. 5773-5779, 2012.

[10] Y. Gu and F. Ding, "Parameter estimation for an input nonlinear state space system with time delay," Journal of The Franklin Institute, vol. 351, no. 12, pp. 5326-5339, 2014.

[11] R. Waschburger and R. K. H. Galvão, "Time delay estimation in discrete-time state-space models," Signal Processing, vol. 93, no. 4, pp. 904-912, 2013.

[12] S. Shimmyo, T. Sato, and K. Ohnishi, "Biped walking pattern generation by using preview control based on three-mass model," IEEE Transactions on Industrial Electronics, vol. 60, no. 11, pp. 5137-5147, 2013.
[13] H. Tokutake, S. Okada, and S. Sunada, "Disturbance preview controller and its application to a small UAV", Transactions of the Japan Society for Aeronautical and Space Sciences, vol. 55, no. 1, pp. 76-78, 2012.

[14] N. Wang, K. E. Johnson, and A. D. Wright, "FX-RLS-based feedforward control for LIDAR-enabled wind turbine load mitigation," IEEE Transactions on Control Systems Technology, vol. 20, no. 5, pp. 1212-1222, 2012.

[15] L. Ferkl and Jan Široký, "Ceiling radiant cooling: comparison of ARMAX and subspace identification modelling methods," Building and Environment, vol. 45, no. 1, pp. 205-212, 2010.

[16] R. Whalley and A. Abdul-Ameer, "Heating, ventilation and air conditioning system modelling," Building and Environment, vol. 46, no. 3, pp. 643-656, 2011.

[17] Y. Yao, M. Huang, J. Mo, and S. Dai, "State-space model for transient behavior of water-to-air surface heat exchanger," International Journal of Heat and Mass Transfer, vol. 64, pp. 173192, 2013.

[18] F. Liao, Y. Liao, and J. Deng, "The application of predictor feedback in designing a preview controller for discrete-time systems with input delay," Mathematical Problems in Engineering, vol. 2016, Article ID 3023915, 10 pages, 2016.

[19] L. Pekař and R. Prokop, "Algebraic robust control of a closed circuit heating-cooling system with a heat exchanger and internal loop delays," Applied Thermal Engineering, vol. 113, pp. 1464-1474, 2017.

[20] Z. Ning, L. Zhang, J. De Jesus Rubio, and X. Yin, "Asynchronous filtering for discrete-time fuzzy affine systems with variable quantization density," IEEE Transactions on Cybernetics, vol. 47, no. 1, pp. 153-164, 2017.

[21] L. Li and F. Liao, "Robust preview control for a class of uncertain discrete-time systems with time-varying delay," ISA Transactions $^{\circledR}$, vol. 73, pp. 11-21, 2018.

[22] X. Yu, F. Liao, and J. Deng, "Robust preview control for a class of uncertain discrete-time Lipschitz nonlinear systems," Mathematical Problems in Engineering, vol. 2018, Article ID 4606389, 15 pages, 2018. 


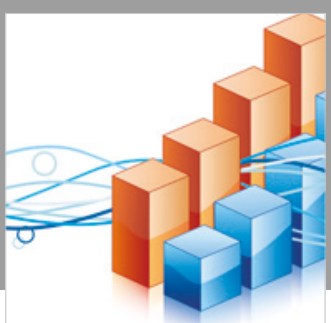

Advances in

Operations Research

\section{-n-m}
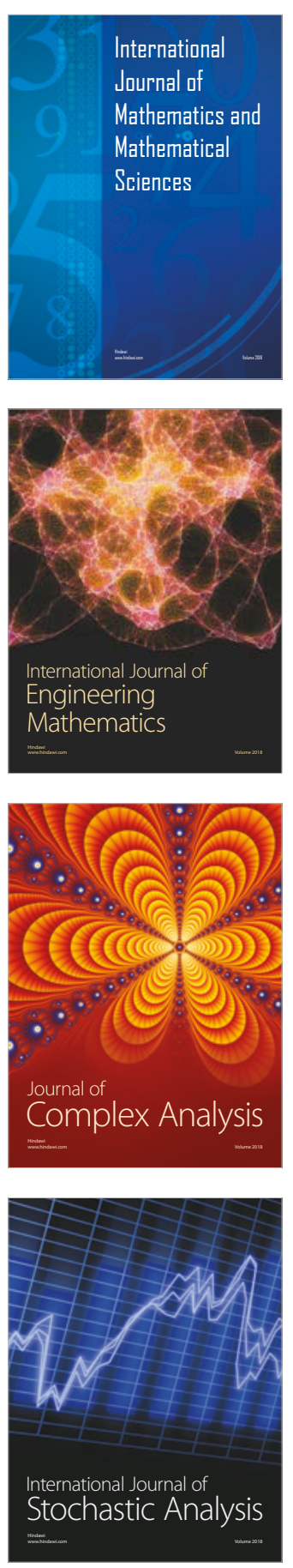
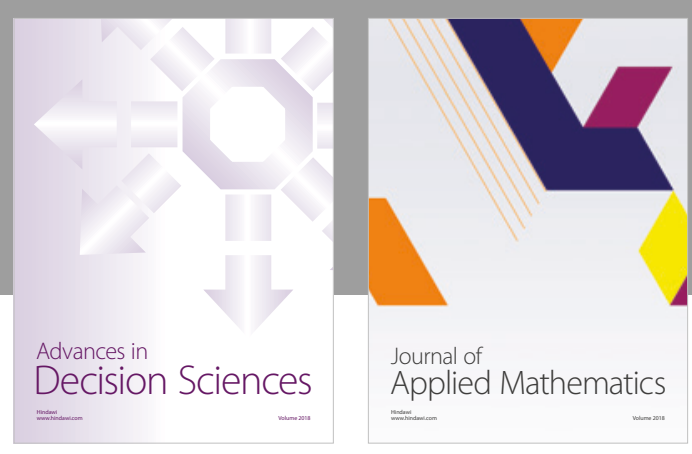

Journal of

Applied Mathematics
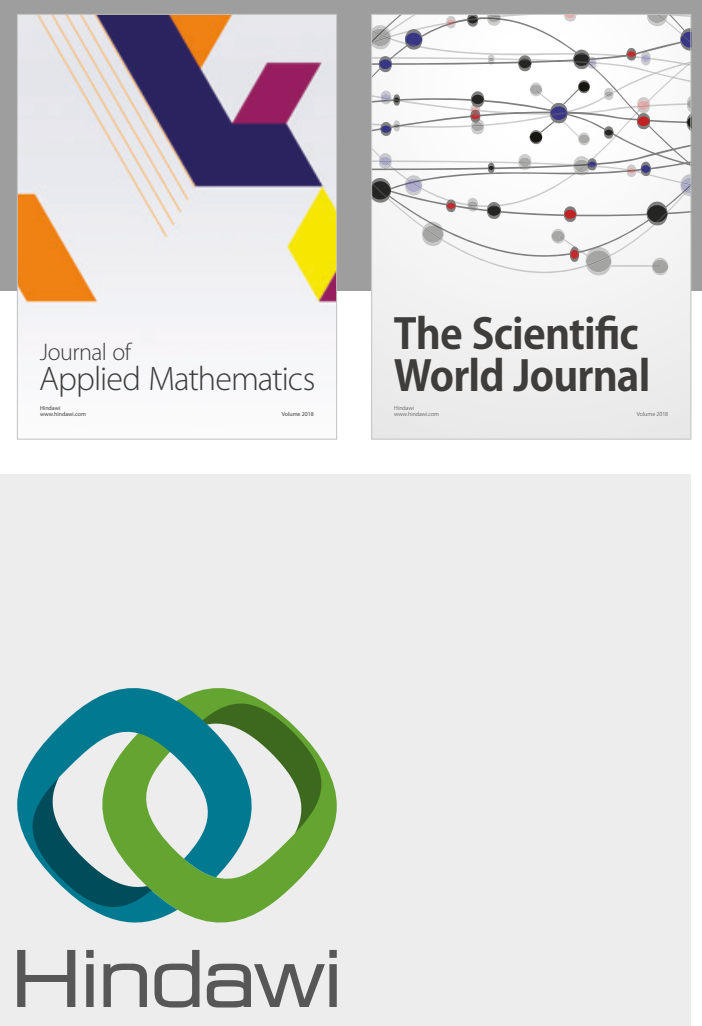

Submit your manuscripts at

www.hindawi.com

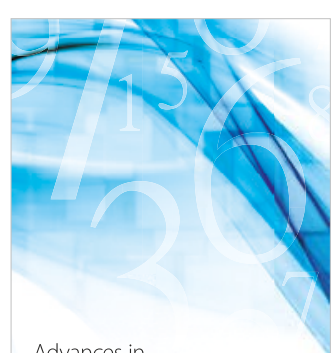

Advances in
Numerical Analysis
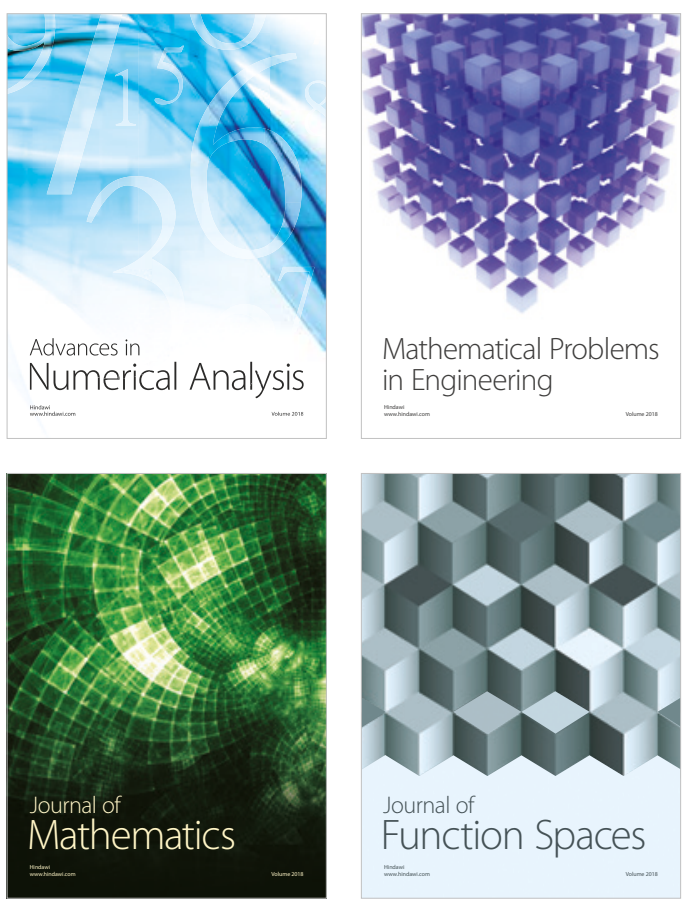

Mathematical Problems in Engineering

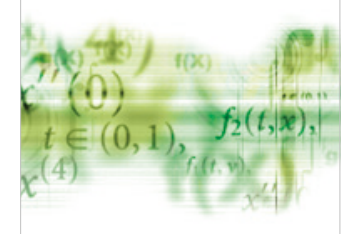

International Journal of

Differential Equations

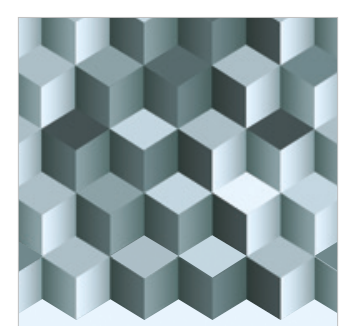

Journal of

Function Spaces

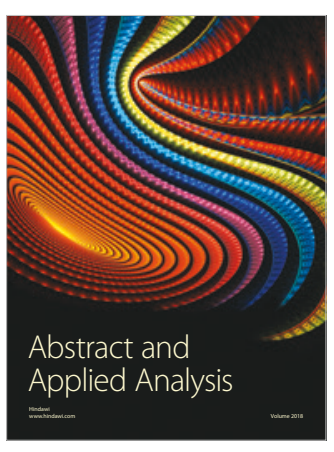

The Scientific

World Journal

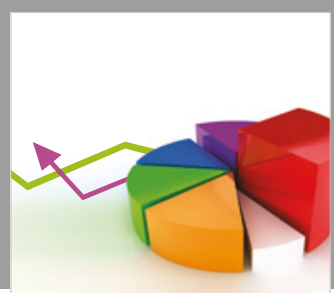

Journal of

Probability and Statistics
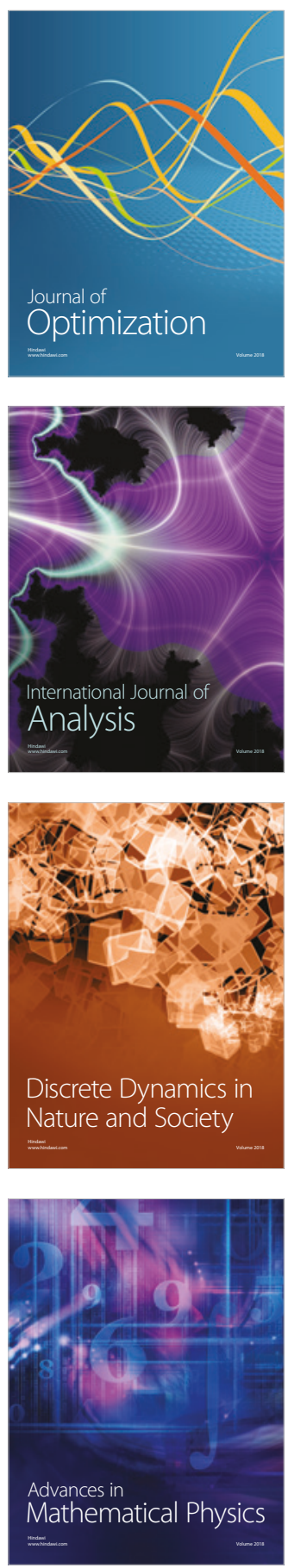